\title{
The Potential of Educational Robotics in Teacher Education
}

\author{
Dmitry A. Boyarinov* (a), Anna E. Samarina (b) \\ (a), (b) Smolensk State University, 214000, Smolensk (Russia), 4 Prjevalskogo street, \\ dmboyarinov@mail.ru
}

\begin{abstract}
The role of robotics in the educational process is in the focus of many modern studies. The problem of identifying the potential of educational robotics in pedagogical education and methods for realizing this potential remains mostly unexplored. The purpose of this study is to identify the organizational and pedagogical conditions for teaching and learning of students of pedagogical majors in the field of educational robotics.

The research method applied in the study of this problem was the survey administered to 40 undergraduate and graduate students in the Russian Federation and the Republic of Kazakhstan. We analyzed the capabilities of modern robotic platforms and developed a system of indicators and the methodology for assessing the academic success of students in the process of studying educational robotics. In design, robotics is based on analysis of the design and software content of projects and the effectiveness of their implementation; in the competitive field - on the analysis of the complexity of tasks, in STEM learning - on the analysis of the ability to effectively implement interdisciplinary connections. Identified organizational and pedagogical conditions are based on four key principles: multi-platform principle; the leading role of project activities of students in the educational process; individualization and differentiation of the educational process; ensuring the continuity of the educational process. Organizational and pedagogical conditions for training of students of pedagogical majors in the field of educational robotics, based on the multi-platform principle, allow us to individualize and intensify the learning process of the future teacher of robotics.
\end{abstract}

Keywords: educational robotics, teacher education, student-centered education, project-oriented learning, multi-platform principle.

\section{(C) 2020 Dmitry A. Boyarinov, Anna E. Samarina}

This is an open access article distributed under the terms of the Creative Commons Attribution License (CC BY 4.0), which permits unrestricted use, distribution, and reproduction in any medium, provided the original author and source are credited.

Published by Kazan federal university and peer-reviewed under responsibility of IFTE-2020 (VI International Forum on Teacher Education) 


\section{Introduction}

Educational robotics is a modern and effective didactic tool that organically complements the virtual learning environment. This is due to the fact that all students need fast and high-quality access to effective science, technology, engineering, and math (STEM) learning in the learning process at all levels of education. As technological advances and the resulting changes come to the education system at an astonishing rate, students "need exposure to the possibilities available to them as they work toward high school graduation, trade schools, community college, university, and/or the workforce" (Casey, Gill, Pennington, \& Mireles, 2018, p. 1532-1533). Educational robotics is one of the ways of such familiarization. It provides means to reflect in the learning environment the rapid progress of information and communication technologies that permeate modern society.

\section{Purpose and objectives of the study}

The purpose of this study is to identify the organizational and pedagogical conditions for the learning of students of pedagogical majors in the field of educational robotics.

\section{Literature review}

The role of robotics in the educational process is in the focus of many modern studies. Different areas of educational robotics (ER) are analyzed:

1) as a part of computer science devoted to the study of the fundamentals of automated device management (Casey et al., 2018);

2) as a way of teaching programming (Keane, 2019; Gagarina \& Gagarin, 2019);

3) as an element of STEM learning (Clark-Wilson, 2019; Ioannou \& Makridou, 2018; Gagarina \& Gagarin, 2019);

4) as a sports / competitive sphere (Keane, 2019);

5) as a tool for organizing project activities (Chandrasekaran, Stojcevski, Littlefair, \& Joordens, 2013; Alkhaldi, Pranata, \& Athauda, 2016);

6) as a gaming (entertaining) robotics (Keane, 2019). 
Currently, there is a significant shortage of teachers in educational robotics in Russian pedagogical practice (Gagarina \& Gagarin, 2019). Accordingly, the issue of learning teachers in the field of educational robotics is relevant. At the same time, the problem of identifying the potential of ER in pedagogical education and methods for realizing this potential remains not completely explored. One pedagogical study states that educational robotics "may be useful in enhancing critical thinking and problem-solving skills, in conjunction with collaboration with peers" (Casey et al., 2018, p. 1533). The authors of the study relied on the use of the Roamer® platform. In the framework of this study, the main goals of educational activity were reduced to the need to develop students' understanding of the interconnections of theoretical mathematics and program code as an applied field of knowledge. The goal was also to enable students to write program code for a robot that should perform a specific task and which other students could use in their activities (Casey et al., 2018, p. 1538). The main focus of the study Casey et al. was aimed at bridging the digital divide. This study was applied primarily to students whose first language is other than English and students from underserved populations.

A study by Keane (2019) highlighted a wide range of possible areas of application of robotics in education. In this study, three main areas can be distinguished:

1) Educational robotics as a way of teaching programming, and, more broadly, STEM education. Keane notes in this context that the widespread educational robotics in the practice of educational organizations is caused primarily by a growing interest in STEM subjects (science, technology, engineering, and mathematics) (Keane, 2019, p. 7). At the same time, the use of this technology contributes to the formation of students' interest in the educational process, the development of critical thinking, creativity, positive educational motivation, and interest in cooperation in learning (Keane, 2019, p. 6).

2) Educational robotics as a sports / competitive field. Currently, there are two large international organizations that hold regular international competitions in robotics: FIRST and VEX (Keane, 2019, p. 2). In particular, the FIRST mission is "To transform our culture by creating a world where science and technology are celebrated and where young people dream of becoming science and technology leaders" (Keane, 2019, p. 2-3).

3) Educational robotics as a game (entertaining) robotics. Keane notes that some of the robots used in the learning process are a cross between a toy and a didactic tool (Keane, 2019, p. 6). 
In a study by Clark-Wilson (2019), educational robots were also considered primarily as an element of STEM education. In general, according to Clark-Wilson (2019), robotics plays a significant role in the formation of "a mathematical environment within which to explore, express, and communicate mathematical ideas" (Clark-Wilson, 2019, p. 2). Clark-Wilson (2019) also pays particular attention to the need for teachers to be prepared to use technology within mathematics teaching (Clark-Wilson, 2019, p. 7). As the main training tools, he considers Massive open online courses (MOOCs) and the use of compulsory or elective courses, which are an organic part of teacher education and focused on the use of modern technologies in education.

In a study by Ioannou and Makridou (2018), educational robotics was considered as an element of STEM education with a focus on student-centered education and the development of computational thinking. Moreover, educational robotics primarily acts as "a useful supporting tool for the development of cognitive skills, including Computational Thinking (CT), for students of all ages" (Ioannou \& Makridou, 2018, p. 2531). In general, Ioannou \& Makridou (2018) evaluate the potential of educational robotics in education very highly, as a necessary tool that allows students to gain experience in interacting with a specific object in the process of knowledge construction (Ioannou \& Makridou, 2018, p. 2532). The reason for this conclusion is the well-known thesis of constructionism learning theory "one gains knowledge while interacting with physical artifacts and being an active learner using technologies" (Ioannou \& Makridou, 2018, p. 2535). These authors note the significant stability, the invariability of the roles of the teacher and students in all the various learning scenarios using educational robotics. A teacher in such conditions invariably acts as a facilitator: "The instructor typically assumed the role of a facilitator of the knowledge and provided support for technical issues" (Ioannou \& Makridou, 2018, pp. 2537-2538). Students actively interact with robotic platforms and thereby form their knowledge on an activity basis. In all such scenarios, a "student-centered, constructivist learning environment" is formed (Ioannou \& Makridou, 2018, p. 2538).

Ioannou \& Makridou (2018) emphasized that it is very difficult to assess the level of the practical usefulness of certain robotic platforms for solving certain didactic problems (Ioannou \& Makridou, 2018, p. 2538). A very important conclusion made in this study and fully shared by us is the need to create a repository of robotic platforms, which is "A compilation of a database with all available platforms, capabilities, pros/cons, etc.” (Ioannou \& Makridou, 2018, p. 2541).

In a study by Alkhaldi et al. (2016) educational robots are considered as a tool for organizing project activities in the context of Web-based learning environments and the use of various online learning tools (Alkhaldi et al., 2016, p. 330). 
These researchers place educational robots in the context of the concepts of "Remote Laboratory" and "Virtual Laboratory". Remote Laboratory is characterized by the physical distance of the experimenter from the experiment. This situation occurs, for example, when students remotely move robots in the laboratory (Alkhaldi et al., 2016, p. 330). Virtual (Simulated) Laboratory is based on software tools that create a simulation of laboratory devices that students can access. As noted by Alkhaldi et al. (2016), virtual and remote laboratories for programming robots, currently is one of the most popular methods for the practical use of educational robotics (Alkhaldi et al., 2016, p. 332).

A significant advantage of using educational robotics is the ability to integrate with learning management systems and organization of group work forms (Alkhaldi et al., 2016, p. 344). Another positive factor is the possibility of creating an experimental environment that allows emphasizing the pedagogical goal of the experiment while abstracting students from distracting difficulties that may arise in a real experiment (Alkhaldi et al., 2016, p. 344).

In a study by Chandrasekaran et al. (2013), educational robots were considered as a tool for organizing project activities in the framework of the design-based learning environment (Chandrasekaran et al., 2013, 1109). The ultimate goal of their use in the educational process is to create a "constructive learning environment in which students are able to integrate sustainable design into engineering" (Chandrasekaran et al., 2013, 1110). According to Chandrasekaran et al. (2013), ideas of Project-Oriented Design-Based Learning (PODBL) will be implemented within the framework of such a learning environment. The authors define PODBL as "a method or a framework, which will balance the teaching and learning by incorporating design, creativity, innovation and communication skills in the engineering curriculum" (Chandrasekaran et al., 2013, 1111). These researchers highlighted the advantages of teamwork in design-based learning (Chandrasekaran et al., 2013, p. 1116). The conclusion about the special relevance of group forms of educational activity in the context of the use of educational robotics seems very promising to us. Thus, an analysis of modern research in this field allows us to conclude that, despite the high level of development of problems of educational robotics, there is currently no system of organizational and pedagogical conditions for the learning of students of pedagogical majors in the field of educational robotics.

The purpose of this study is to identify the organizational and pedagogical conditions for the learning of students of pedagogical majors in the field of educational robotics. Organizational and pedagogical conditions should include a system of principles, criteria and quality indicators for their achievement. A necessary condition for the development of such organizational and pedagogical conditions is the analysis of the didactic potential of relevant robotics platforms in relation to the field of teacher education. 


\section{Methodology}

The following methods were used in the study: the study and analysis of pedagogical literature, a comparative analysis of the experience of learning robotics to students of different ages, sociological surveys and interviews of students and teachers. The practical part of the study was held from July 1, 2017, to December 31, 2019, with the participation of students of Smolensk State University (Smolensk, Russian Federation) and Arkalyk State Pedagogical Institute (Arkalyk, Republic of Kazakhstan) in the educational program "Pedagogical Education" ("Mathematics", "Physics" and "Computer Science" programs). In total, the study involved 40 people.

\section{Results}

In the theoretical part of our study, we identify the system of organizational and pedagogical conditions for the learning of students of pedagogical majors in the field of educational robotics.

Organizational and pedagogical conditions are based on four key points:

1) Implementation of the multi-platform principle, according to which learning should be implemented using a variety of robotic platforms, and students should develop competencies in analyzing the didactic properties of the platforms and choosing the platform in accordance with the learning objectives.

2) Ensuring the continuity of the educational process, including the transition from one platform to another.

3) The leading role of project activities of students in the educational process.

An important competency is the ability to work on a project to create a model or prototype of a robotic device. During the work on the STEM project, students choose a significant practical task, then they can use knowledge from different subject areas - physics, technologies, math, design, programming. Students must set a goal and determine the objectives of the project, outline the stages of implementation, complete the assembly and constructive basis, write and debug the program, and present the project in public. Work can take place in group form, which allows the formation of soft skills, the ability to collaborate, distribute roles, communicate. Work on the project develops the engineering thinking of students.

4) Individualization and differentiation of the educational process. 
We also developed a system of indicators and a methodology for assessing the academic success of students in the process of studying ER based on an analysis of the development of creative and engineering skills. In design robotics it is based on analysis of the design and software content of projects, the effectiveness of their implementation, in the competitive field - on the analysis of the complexity of tasks, in STEM learning - on the analysis of the ability to effectively implement interdisciplinary connections.

We distinguish the following criteria:

1) The quality of the learning project.

2) The quality of the implementation of the project.

3) The complexity of the educational task solved within the project.

4) The level of interdisciplinary connections implemented in the course of the completion of the project.

We offer a system of performance indicators that meet each of the four criteria:

1) The main performance indicators for the first criterion are expert assessments of the quality of the project, given by the tutor and the learning group in which the project was completed.

2) Among the performance indicators for the second criterion, we propose to distinguish quantitative and qualitative. Quantitative indicators include the degree to which the completed educational project meets the requirements presented by the tutor to it at the stage of setting the task. Qualitative indicators include the level of coordination of actions of team members in the process of implementing collective forms of work in making the project and the level of subjective satisfaction with the result of each student.

3) The indicator of effectiveness according to the third criterion is a quantitative characteristic that describes the complexity of the solved educational task. Such a characteristic can be obtained, for example, based on an analysis of the structure of the formal model of this task.

4) The performance indicator according to the fourth criterion is a quantitative characteristic, which is the share of interdisciplinary information in the total amount of scientific/educational information contained in the project. 
The learning course created in accordance with the developed theoretical principles on the material of the discipline "Fundamentals of Robotics" was used in teaching undergraduate students, the course "Educational Robotics" - in teaching graduate students. In the course of the students' reflection on the experience of teaching the basics of robotics and its educational aspects, qualitative results were obtained that are consistent with the described theoretical provisions.

The main factor of the effectiveness of teaching ER is the study of various robotic platforms, a comparison of the characteristics of hardware and software, the identification of similarities, which allows us to develop common patterns in teaching and the identification of differences, allowing us to organize training for different levels and for different purposes.

For example, when comparing the Lego Mindstorms and Arduino platforms, students noted a commonality of the principles of programming and design, and differences - the preferred applicability of the former to teaching schoolchildren, and the latter to students of high school.

In the experimental part of our study, students studied the basics of robotics and its application in the educational process based on Robotic sets ROBBO (Scratchduino), Arduino, Lego Mindstorms.

For execution, tasks of five different types were proposed:

1) Learning the basics of programming in visual and textual environments (Robolab for Lego Mindstorms, Scratch and Arduino IDE for ROBBO and Arduino).

2) The solution of tasks in a game form, such as control of moving wheeled robots, virtual objects in a software environment.

3) The solution of standard tasks of competitive robotics - movement along the line, identification of obstacles, etc. based on ROBBO and Lego Mindstorms devices.

4) Studying the basics of electrical engineering and the assembly of electronic circuits based on Arduino and programming standard models of real electrical devices.

5) Creation of student's own technical projects using additional structural elements and materials based on Arduino.

At the end of the assignment, students were asked to answer the questionnaire about the results. 
During practical classes in robotics, 2nd-year students of the educational program "Pedagogical Education" ("Mathematics and Informatics", "Physics and Informatics" programs) studied working with educational robotic designers based on Arduino and Lego Mindstorms using visual and textual programming environments. According to the results of the practice, students answered the questionnaire.

The vast majority of students did not meet before classes or only heard about robotics $(54.9 \%$ and $36.4 \%$, respectively), only $9.1 \%$ had previously worked in robotics.

Figure 1. Level of the familiarization with ER of Smolensk State University students

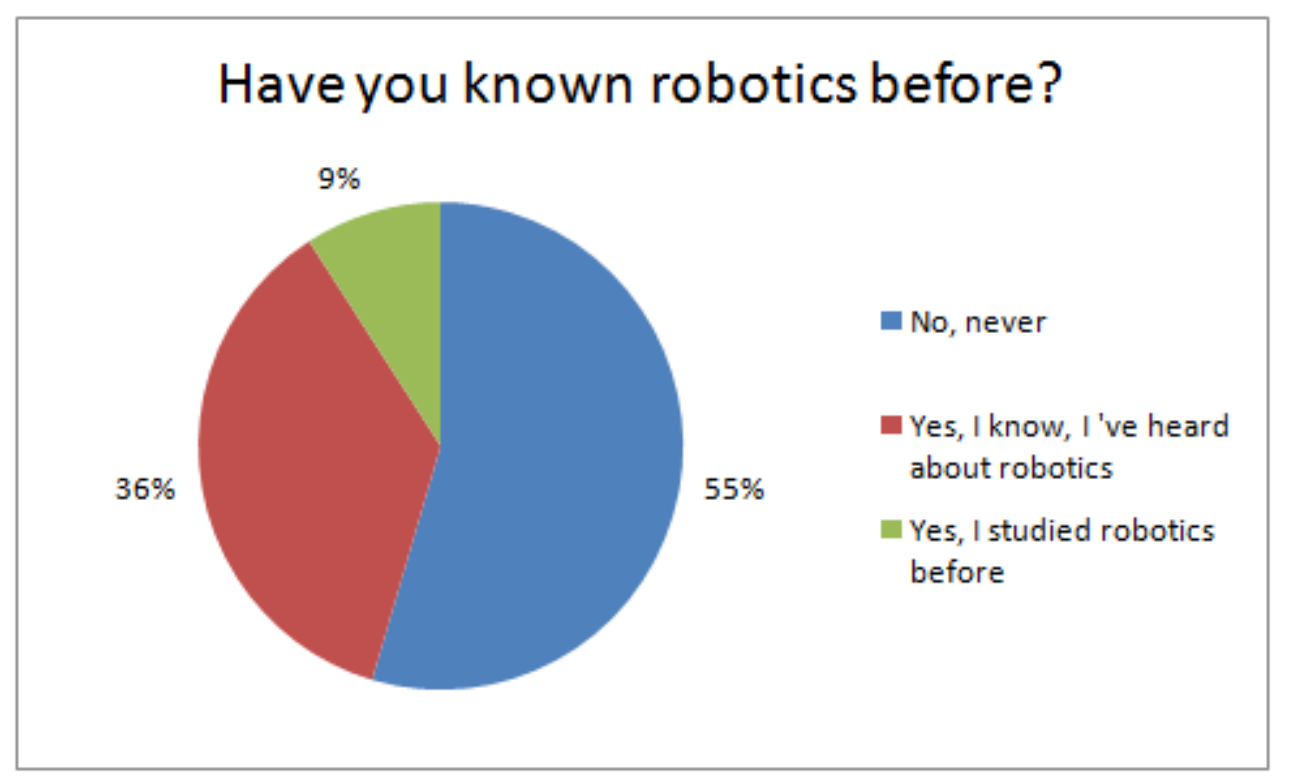

On the question of preferences, the opinions of the respondents were divided: $81.9 \%$ - Arduino, $18.2 \%$ Lego Mindstorms. 
Figure 2. Rating of capabilities of Lego Mindstorms constructor

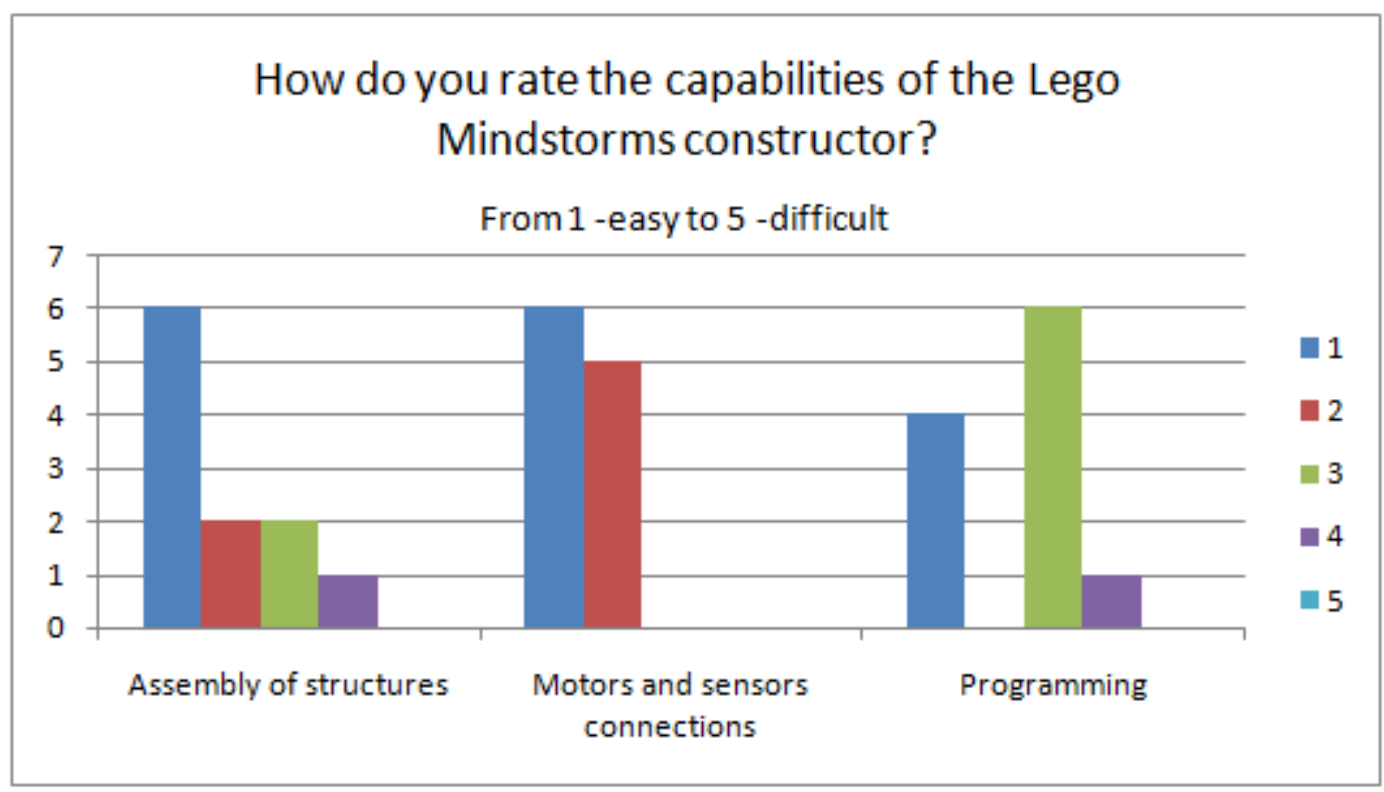

Figure 3. Rating of capabilities of Arduino based constructor

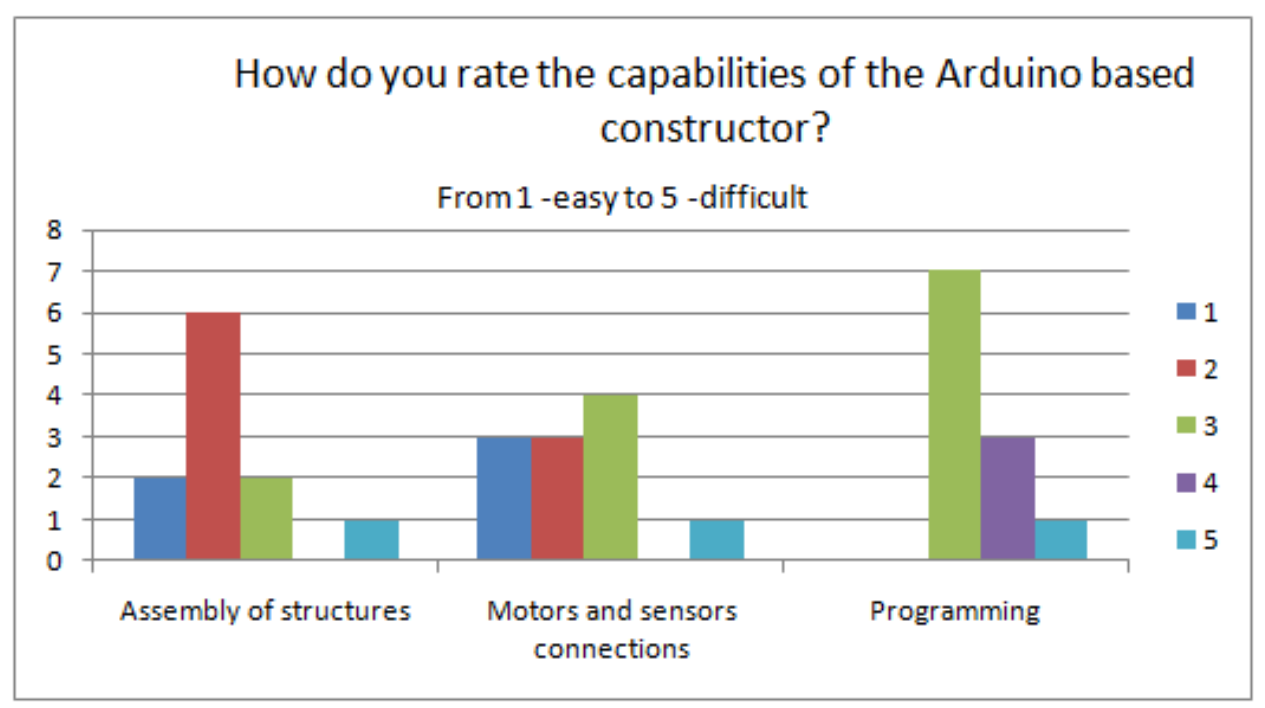

According to the obtained results, students found working with an Arduino-based designer a little more complicated than Lego Mindstorms, although both sets did not cause many difficulties. 
Figure 4. Features comparison of constructors

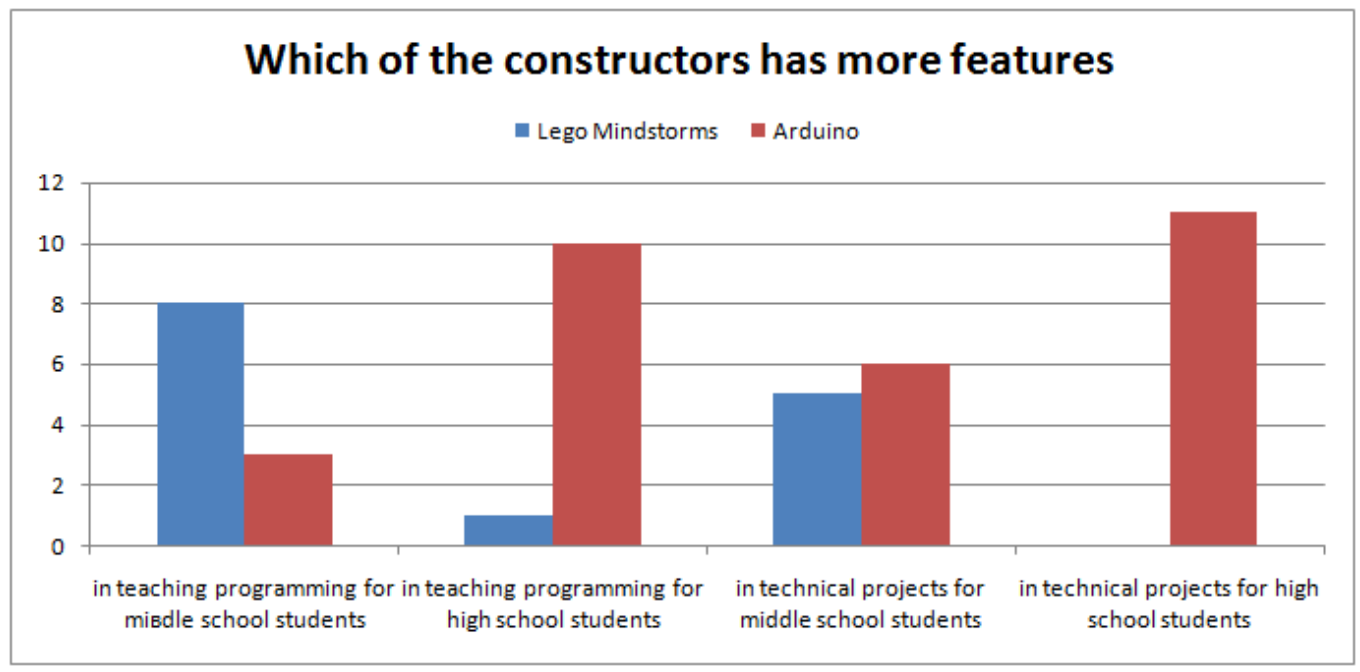

When answering a question about difficulties in working with robotic platforms, $63 \%$ of the respondents noted some difficulties in programming for Arduino in a text environment, only $27.3 \%$ had difficulty visual programming for Lego Mindstorms, and 9.1\% had difficulty assembling structures for robots on Lego.

Students also noted in the reviews that both platforms (Lego Mindstorms and Arduino) have a common programming principle, the same sequence of work with projects (first assembly, then programming), suitable for different age groups. According to respondents, Lego Mindstorms equipment has a greater emphasis on design and is more suitable for teaching schoolchildren of younger and middle age, and Arduino - for college students and high school students, as it is somewhat more complex and has more features and expandability due to additional electronic components that are not available in Lego Mindstorms. Thus, the study of robotics using different platforms allowed students to understand the general principles of ER, as well as to identify didactic opportunities for use them in teaching different age categories of learners and to solve different educational tasks.

During the studying on educational robotics of the Arkalyk State Pedagogical Institute (Arkalyk, Republic of Kazakhstan), students studied the capabilities of Arduino-based robotic equipment using Scratch / mBlock and Arduino IDE software.

The survey involved 2-nd and 3-rd year students of the educational program "Pedagogical education" ("Mathematics", "Physics" and "Computer Science" programs). 
Students were also practically untrained in ER: before the participation in the experiment, only $8.3 \%$ had been engaged in robotics before, and the vast majority were not familiar or only heard about it (33.3\% and $58.3 \%$, respectively).

Figure 5. Level of the familiarization with ER of Arkalyk State Pedagogical Institute students

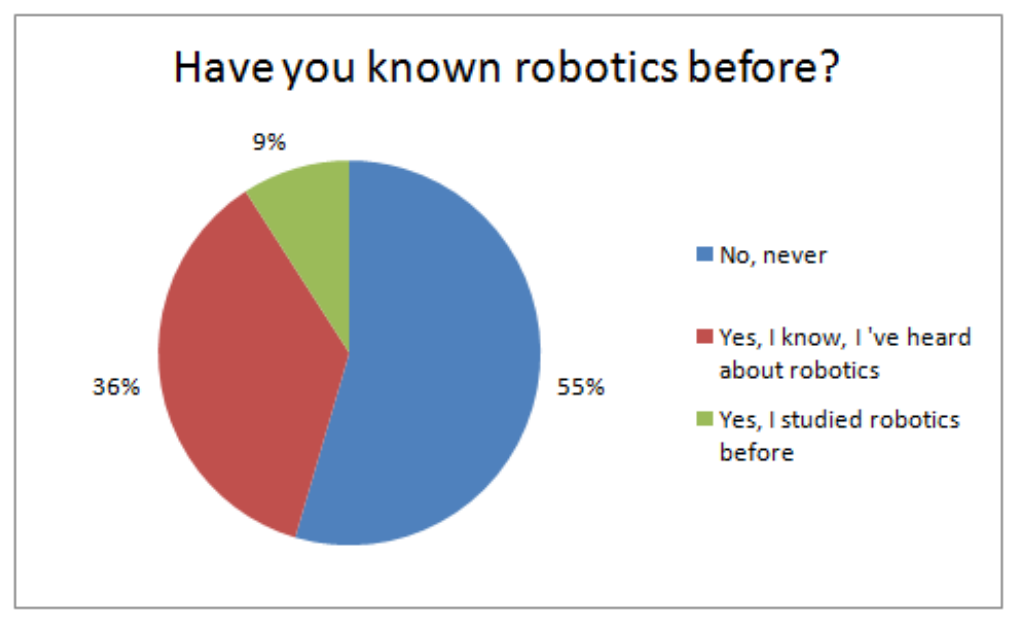

Familiarity with the basics of robotics on Scratch / mBlock and Arduino left a positive impression in 100\% of respondents.

When asked about the capabilities of the Arduino-based designer for assembly and programming, opinions were divided as follows.

Figure 6. Rating of capabilities of Arduino based constructor

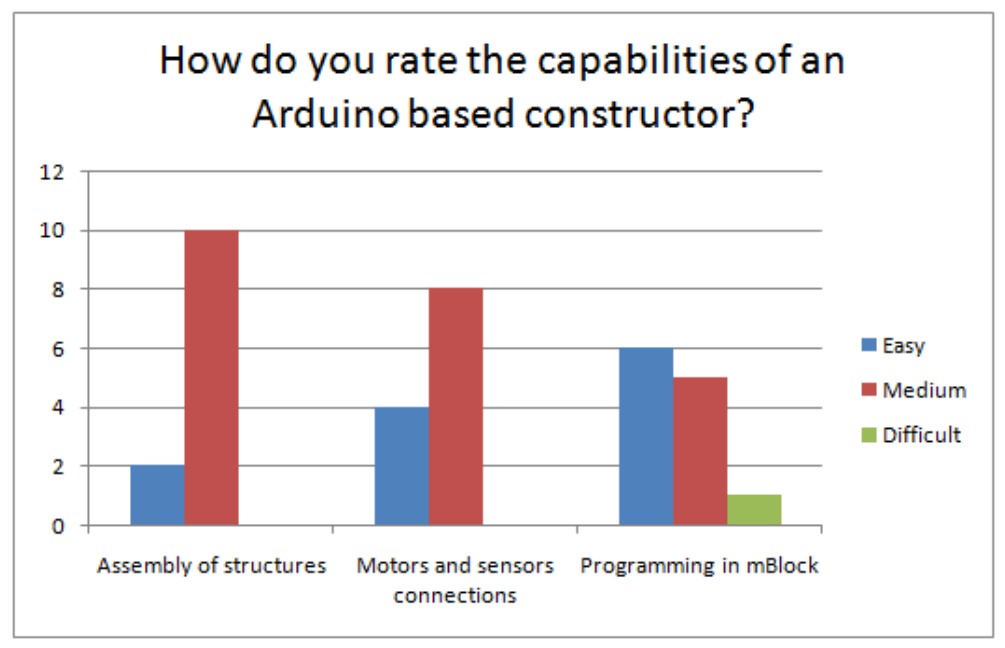


In the question of difficulties in work, the answers were distributed as follows.

Figure 7. Rating of difficulties of Kazakh students

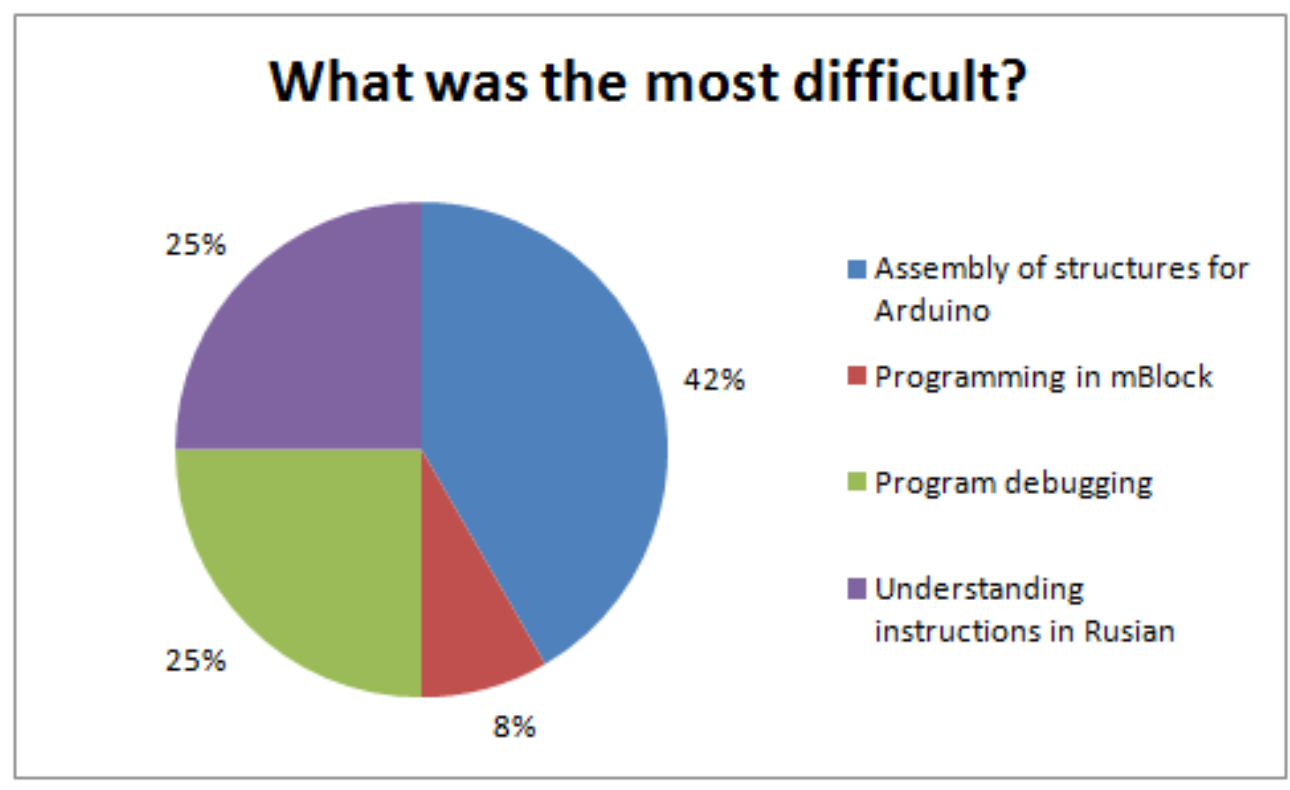

Comparing the results of the survey of Russian and Kazakh students about the results of learning ER, we can note some general trends:

1) Approximately the same initial level of familiarization with ER of students.

2) A generally positive attitude towards educational robotics.

3) Approximately the same level successes and difficulties in programming and assembling structures.

4) The language of instructions turned out to be an additional significant negative factor for Kazakh students.

In 2017 and 2018, classes in educational robotics were held with master students of the educational program "Pedagogical Education" ("Information Technologies in Education" and "Physics and Mathematics Education" programs). In the learning process, Robotic Scratchduino kits with the RobboScratch visual programming environment and Arduino based kits with the Arduino IDE text environment were used. 
During surveys and conversations in the learning process, students mentioned:

1) The preference for using ROBBO equipment with a visual programming environment in-game robotics for young students, for teaching programming middle-school students.

2) Ample opportunities to use kits based on Arduino, not only for teaching text programming to high school students but also for ensuring project activities in STEM education.

\section{Discussions}

We have analyzed the capabilities of modern robotic platforms in relation to the tasks set in the research. The following features of robotic platforms were identified.

Robotic kits based on Lego Mindstorms platform are widely distributed in the international and Russian education and are actually the standard for many robotics competitions. Lego tools make it possible to create different models of robots (wheeled, tracked, walking), which allows us to study the operation of mechanisms. For programming, we use the visual block programming environment Robolab, which is proprietary software. The advantages of this platform include wide methodological support, the availability of software not only for programming but also for creating methodological and educational materials, creating design schemes using the 3D Lego Digital Designer. The shortcomings include accessibility and extensibility, limited by financial conditions, low build strength, some "childishness" of the whole platform, limited possibilities of moving to the next level - to adult programming, difficulties in constructing practical technical projects (Ovsyanitskaya, Ovsyanitsky, D.N., \& Ovsyanitsky, A.D., 2014; Ovsyanitskaya, Ovsyanitsky, D.N., \& Ovsyanitsky, A.D., 2015; Koposov, 2015; Filippov, 2018; Gagarina \& Gagarin, 2019).

A variety of kits based on the Arduino platform take 2nd place in the distribution in Russia (Gagarina \& Gagarin, 2019) due to financial availability and the use of free hardware and software. The advantages of this platform include easy extensibility due to compatibility with a huge class of electronic components, a variety of programming environments, both visual and text, allowing us to use the Arduino platform for learners of different age categories. A variety of reference materials from the user community provides all the necessary support. Among the shortcomings are often highlighted the lack of a unified program, unified approaches to use in the educational process.

It should be noted that Arduino-based kits in the process of design and construction of devices require the use of additional materials, components, and fixtures that are not included in the kit. On the one hand, this 
is an obvious shortcoming; on the other hand, it stimulates students to develop creative and engineering thinking, knowledge about materials and how to process them. This allows the use of such kits in interdisciplinary design activities in the STEM field (Koposov, 2015).

The Russian robotic platform ROBBO (Scratchduino) includes Arduino-based kits for various purposes: for programming the movement of a wheeled robot (Roboplatform), for studying working with sensors and creating smart device projects (Laboratory), a kit for teaching the basics of circuitry based on Arduino platform. As software, free software is used - the RobboScratch visual programming environment and the Arduino IDE.

The advantages of this platform include affordable software, the availability of methodological support, a community of users for the exchange of projects and materials, providing not only entry-level game-based learning but also studying the basics of circuitry and switching to self-assembly of automated devices and programming their work as an "adult" level. The disadvantages include some fragility of kits and low prevalence in Russian education (Grigoriev \& Vinnitsky, 2017; Tarapata \& Samylkina, 2017).

Makeblock platform is a novelty in Russian education. The platform has products for various ages and educational stages: for gaming robotics, for teaching programming, for the study of the Internet of things and smart devices (AI \& IoT), construction kits. Advantages include financial affordability, usability - ease of assembly, structural strength, programming capabilities in a Scratch based visual environment and text languages Arduino IDE and Python. The equipment is compatible with Lego Mindstorms and Arduino components. The disadvantage is still insufficient methodological support and low prevalence (Kosachenko, 2019).

The Raspberry PI platform is a higher-level product; its main feature is the focus on teaching programming and suitability for teaching high school students and students (Koposov, 2015).

After analyzing these platforms, we can identify some common qualities:

1) The presence of a visual programming environment that facilitates inexperienced users' familiarity with algorithms and device management.

2) The possibility of modifying the structural part of the device: tools can assemble several models of devices from existing or additional components or materials.

3) For the assembly of more complex (not standard) structures, it is necessary to study the fundamentals of the operation of mechanisms - types of gears, wheels, pivots, levers, etc. The 
methodological support of some platforms includes such content (Lego Mindstorms, Makeblock) (Koposov, 2015; Filippov, 2018).

4) Many platforms have not only PC programs, but also mobile applications for controlling robotic devices (Makeblock, Scratchduino, Lego Mindstorms), which reflects the general trend towards the spread of mobile devices and multiple platforms.

For learning in robotics in educational institutions, the choice of such equipment is preferred, which can be used with students of different ages at different levels of programming and technology.

The educational robotic platform should be used by younger schoolchildren in game-based learning, in middle school age - when learning the basics of programming. High school students should be able to create various technical projects, devices on the basis of the selected equipment, and be able to independently choose and combine both structural and electronic components. In addition, when used in educational institutions, equipment must meet the requirements of strength, stability, and software accessibility for the corresponding age categories of learners (Gagarina \& Gagarin, 2019).

\section{Conclusion}

Organizational and pedagogical conditions for the preparation of students of pedagogical majors in the field of educational robotics, based on the multi-platform principle, allow us to individualize and intensify the learning process of the future teacher of robotics.

The learning process for future teachers of robotics should include the study of various robotic platforms and miscellaneous equipment, the study of various software tools for robotic devices suitable for teaching learners of different ages.

A prerequisite for the organization of teacher education in the field of robotics is the creation of a repository of robotic platforms. Developing the approach of Ioannou and Makridou (2018), we mean the repository as a database that integrates information about all available robotic platforms, their didactic properties and the corresponding pedagogical technologies. In accordance with the developed provisions, it is necessary to develop and test the content of learning robotics to students of pedagogical majors, teaching methods for robotics in basic and supplementary education, which form a set of further tasks related to the evolution of our study. 


\section{References}

Alkhaldi, T., Pranata, I., \& Athauda, R. I. (2016). A review of contemporary virtual and remote laboratory implementations: observations and findings. Computers \& Education, 3(3), 329-351. https://doi.org/10.1007/s40692-016-0068-z

Casey, J. E., Gill, P., Pennington, L., \& Mireles, S. V. (2018). Lines, roamers, and squares: Oh my! using floor robots to enhance Hispanic students' understanding of programming. Education and Information Technologies, 23, 1531-1546.

Chandrasekaran, S., Stojcevski, A., Littlefair, G., \& Joordens, M. (2013). Project-oriented design-based learning: aligning students' views with industry needs. International journal of engineering education, 29(5), 1109-1118.

Clark-Wilson, A. (2019). Mathematics Education and Technology. In A. Tatnall (Ed.), Encyclopedia of Education and Information Technologies [eBook edition]. Springer, Cham. https://doi.org/10.1007/978-3-319-60013-0_96-1

Filippov, S. A. (2018). Robotics lessons. Design. Traffic. Control (2nd ed.). Moscow: Knowledge Laboratory.

Gagarina, D. A., \& Gagarin, A. S. (2019). Robotics in Russia: educational landscape. Part 1 \& Part 2. Moscow: NRU HSE.

Grigoriev, A. T., \& Vinnitsky, Ju. A. (2017). Implementation of educational programs in the area of "robotics" in a non-specialized secondary school. Akademicheskij vestnik. Vestnik SanktPeterburgskoj akademii postdiplomnogo pedagogicheskogo obrazovaniya [Academic newsletter. Bulletin of the St. Petersburg Academy of post-diploma pedagogical education], 3(37), 57-61.

Ioannou, A., \& Makridou, E. (2018). Exploring the potentials of educational robotics in the development of computational thinking: A summary of current research and practical proposal for future work. Education and Information Technologies, 23, 2531-2544. https://doi.org/10.1007/s10639-0189729-z

Keane, T. (2019). Robotics in Education. In A. Tatnall (Ed.), Encyclopedia of Education and Information Technologies [eBook edition]. Springer, Cham. https://doi.org/10.1007/978-3-319-60013-0_169-1 
Koposov, D. G. (2015). Beginning of engineering education at school. STEM education in Russia. Issue 1 [eBook edition]. London: Intel Education.

http://lbz.ru/metodist/authors/technologia/1/stem_koposov_maket.pdf

Kosachenko, S.V. (2019). Programming training robot mBot [eBook edition]. Moscow: Academy. https://bit.ly/2JjLrFt

Ovsyanitskaya, L.Yu., Ovsyanitsky, D.N., \& Ovsyanitsky, A.D. (2014). Lego Mindstorms EV3 Robot Programming Course in the EV3 Environment: Basic Approaches, Case Studies, and Mastery Secrets. Chelyabinsk: IP Myakotin I.V.

Ovsyanitskaya, L.Yu., Ovsyanitsky, D.N., \& Ovsyanitsky, A.D. (2015). Algorithms and programs of movement along the line of the Lego Mindstorms EV3 robot. Moscow: Perot.

Tarapata, V.V., \& Samylkina, N. N. (2017). Robotics at school. Methodology, programs, projects. Moscow: Laboratory of knowledge. 